\title{
Gold-nanoisland-decorated titanium nanorod arrays fabricated by thermal dewetting approach
}

\section{Dilek Ozden Dinc PhD}

Bioengineering Division, Hacettepe University, Ankara, Turkey; Bio-inspired Materials Research Laboratory, Department of Chemistry, Gazi University, Ankara, Turkey; Department of Vocational School of Health Services, Yuksek Ihtisas University, Ankara, Turkey (corresponding author: dlkozden@gmail.com) Mehmet Yilmaz PhD

Department of Chemical Engineering, Atatürk University, Erzurum, Turkey; Bio-inspired Materials Research Laboratory, Department of Chemistry, Gazi University, Ankara, Turkey

\author{
Saime Sebnem Cetin PhD \\ Department of Physics, Gazi University, Ankara, Turkey \\ Mustafa Turk PhD \\ Department of Engineering, Kırıkkale University, Kırıkkale, Turkey \\ Erhan Piskin PhD \\ Bioengineering Division, Hacettepe University, Ankara, Turkey; \\ Nanobiyomedtek, Ankara, Turkey
}

Solid-state dewetting is a simple and versatile technique for fabricating plasmonic-nanostructure-decorated platforms. However, understanding of the optical properties of these platforms and the effect of the threedimensional (3D) morphology of the underlying substrate on the dewetting of metallic thin films is still needed for developing effective platforms for further applications. Herein, the authors report gold (Au)-nanoisland-decorated 3D titanium dioxide $\left(\mathrm{TiO}_{2}\right.$ ) nanorod (TiNR) arrays fabricated through the thermal dewetting approach. It is demonstrated that the plasmonic behavior of the fabricated platforms can be manipulated by controlling both the initial gold film thickness and annealing temperature. Furthermore, the fabricated platforms exhibited Raman signal enhancement of up to $\sim 10^{2}$ for the probe molecule methylene blue. The surface characteristics of the fabricated platforms were evaluated for biological interactions. For this purpose, osteogenic cells (Saos-2) were seeded on the samples. It was found that the cell behavior was improved on the anisotropic micro-nano pattern of TiNRs and gold-coated TiNR films because of features such as topography and surface chemistry. The authors' results clearly offer simple but important guidance for the creation of surface-enhanced Raman spectroscopy platforms and tissue-integration devices as biomaterials for real-life applications.

$\begin{array}{ll}\begin{array}{l}\text { Notation } \\ I_{\text {reference }}\end{array} & \begin{array}{l}\text { Raman intensity of methylene blue (MB) } \\ \text { on a silicon wafer }\end{array} \\ I_{\text {Sers platform }(n)} & \begin{array}{l}\text { Raman intensity of the adsorbed MB on } \\ \text { sample }(n) \\ \text { imaginary number }\end{array} \\ i & \text { number of MB molecules for the reference } \\ N_{\text {reference }} & \text { sample } \\ N_{\text {Sers platform }(n)} & \begin{array}{l}\text { number of MB molecules for sample }(n) \\ \text { deposition angle }\end{array} \\ \Delta, \Psi & \text { conventional ellipsometric angles } \\ \varepsilon & \text { pseudo-dielectric function } \\ \varepsilon_{\text {real }} & \text { real part of the pseudo-dielectric function } \\ \Theta & \text { angle of incidence }\end{array}$

\section{Introduction}

Titanium dioxide $\left(\mathrm{TiO}_{2}\right)$ is a widely used multifunctional material because of its superior stability, biocompatibility and physical-chemical properties, as well as its great accessibility and moderate cost. ${ }^{1,2}$ Due to their promising application potential in the field of solar cells, photocatalysis, biomaterials and biosensors, titanium dioxide thin films have been intensively studied. Among titanium dioxide thin films, newly developed three-dimensional (3D) titanium dioxide nanorods (TiNRs) produced by wet-chemical techniques have attracted great attention for many applications, but the films manufactured by physical vapor deposition (PVD) techniques have been hardly investigated. PVD is a scope of thin-film-deposition techniques including evaporation, laser-ablation deposition, vacuum-arcbased deposition and many different modes of physical sputter deposition. ${ }^{3}$ Using an oblique-angle-deposition technique, welltilted TiNR arrays have been manufactured mostly by the electron-beam evaporation method ${ }^{4}$ without a catalyst, but thermal evaporation has not been used to produce 3D micro-/ nano-structured TiNR arrays.

The decoration of 3D nanostructured films with plasmonic nanoparticles has attracted increasing interest in recent years for varying applications in medicine, environmental protection and homeland security due to the unique properties that they provide $^{5-7}$ To create such materials, researchers have proposed different approaches, including both top-down and bottom-up methods. ${ }^{8}$ Although top-down approaches seem to be a very effective way to fabricate plasmonic-nanoparticle-decorated 3D platforms in a controlled manner, the high-cost, inevitably timeconsuming and delicate manufacturing process limits their applications. ${ }^{9-11}$ Bottom-up techniques, on the other hand, are undoubtedly a much simpler and more versatile way to create such platforms. However, these methods still face problems due to uncontrolled aggregation of plasmonic nanoparticles and 
requirement for specific chemicals for in situ formation of nanoparticles on/in 3D nanostructured substrates. ${ }^{12,13}$ In this context, the solid-state dewetting approach of thin plasmonic films offers distinctive possibilities to overcome the aforementioned limitations.

Solid-state dewetting of metallic thin films is a simple method that is mainly driven by surface energy minimization by thermal heating. ${ }^{14,15}$ Although the exact mechanism in the dewetting process remains unknown, it is proposed that the essential step in dewetting is the formation of holes in the metallic thin film. ${ }^{16-19}$ These holes then induce the formation of dewetted regions and lead to dewetting of the entire film. Since dewetting is based on atomic diffusion, the process highly depends on both metallic thin-film thickness and annealing temperature. Platforms decorated with metallic nanoparticles, which are fabricated by dewetting of metallic thin films, have been employed mostly as catalysts for growth of nanowires and in magnetic memory and photonic device applications. ${ }^{20-22}$

Owing to the simplicity and ability to control size and separation of nanoparticles, the solid-state dewetting approach has also been investigated in the applications of surface-enhanced Raman spectroscopy (Sers). ${ }^{1,23}$ However, understanding of the optical properties of these platforms and the effect of the 3D morphology of the underlying substrate on the dewetting of metallic thin films is still needed for developing effective Sers platforms.

Sers platforms with 3D structure are used as labels for in vivo detection or as nanosensors for the study of prokaryotic and eukaryotic micro-organisms in non-invasive Raman spectroscopy. ${ }^{24,25}$ Since Sers has the advantage of being able to be used in vivo detection because of its non-effective energy dosage on cells and tissues, ${ }^{26}$ for cell-based applications, it is necessary to use biocompatible Sers platforms in biological tissues or cell cultures to prevent toxicity and to monitor tissue growth, including single-cell analysis. ${ }^{27}$ The shape, structure and size of Sers platforms are important for varying the applications of tissue engineering not only to direct the movements of cells on the surface, but also to provide cell integration, proliferation and differentiation in the scaffold. ${ }^{28-32}$ Since the TiNR topography has characteristics of a 3D structure and can be controlled to produce the desired size and density of nanorods by using the PVD-oblique-angle deposition (OAD) technique, gold ( $\mathrm{Au}$ )nanoisland-decorated TiNR arrays have been examined for cell growth and biocompatibility. Anyhow, the mechanism of cell attachment on the surfaces should be determined for detailed cellular features such as gene expression, phagocytosis and movement.

Herein, the authors investigated the dewetting process of gold thin films with varying thicknesses on 3D TiNR arrays in detail. The optical characteristics of the fabricated samples were characterized by spectroscopic ellipsometry. It was observed that both the initial film thickness and annealing temperature play an important role in the final plasmonic behavior of the platforms. The Sers ability of the platforms was validated experimentally and is discussed with respect to both the initial gold thin-film thickness and annealing temperature. In addition, the biocompatibility of the surfaces was evaluated with Saos-2 osteogenic cells by using adhesion and 3-(4,5-dimethylthiazol-2-yl)-2,5-diphenyltetrazolium bromide (MTT) cytotoxicity tests.

\section{Experimental section}

\subsection{Fabrication of samples}

Silicon (Si) wafer $(001)$ surfaces were first cut $\left(2.5 \times 2.5 \mathrm{~cm}^{2}\right)$ and washed with deionized water, acetone and piranha solution consecutively. To eliminate any contaminants, the precleaned samples were further treated with oxygen $\left(\mathrm{O}_{2}\right)$ plasma at low pressure $(0.2 \mathrm{mbar})$ for $30 \mathrm{~min}$ before titanium (Ti) deposition. Three-dimensional TiNR arrays were fabricated in a PVD system (Nanovak HV, Ankara, Turkey) by using homemade OAD equipment. The 3D TiNR arrays were created at a deposition angle of $\alpha=5^{\circ}$. The thickness of the deposited films was monitored using an Inficon XTM/2 deposition monitor with $0.5 \%$ sensitivity. Base pressure was gained by using both a mechanical pump and a turbo pump, and it was monitored by using a Terranova model 934 wide-range vacuum gauge controller. During deposition, the base pressure was fixed at almost $8 \times$ $10^{-6}$ Torr with a titanium evaporation rate $>30 \mathrm{~nm} / \mathrm{s}$.

Afterward, a thin layer of gold $(5-30 \mathrm{~nm})$ was deposited on the fabricated 3D TiNR arrays in the same system at a similar base pressure $\left(\sim 10^{-6}\right.$ Torr $)$. Note that, for the fabrication of smooth gold films on TiNRs, a large source-substrate distance of $20 \mathrm{~cm}$ and a deposition angle of $90^{\circ}$ were used during thermal evaporation. To perform thermal dewetting, the gold-coated TiNR samples were thermally annealed in a tube furnace at different temperatures ranging from 450 to $750^{\circ} \mathrm{C}$. After $1 \mathrm{~h}$, the samples were cooled for $\sim 60 \mathrm{~min}$ before removing them from the furnace to avoid a sudden decrease in temperature.

\subsection{Characterization}

A Quanta 400F field-emission scanning electron microscope (SEM) with an acceleration voltage of $20 \mathrm{kV}$ was used to characterize the morphologies of all fabricated samples. The SEM images obtained were then analyzed by using the ImageJ image analysis freeware. X-ray photoelectron spectroscopy (XPS) of the samples was also performed using a Specs EA 300 instrument equipped with a monochromatic aluminum (Al) $\mathrm{K} \alpha \mathrm{X}$-ray source.

To characterize the optical properties of the fabricated samples, a spectroscopic phase-modulated ellipsometer (Jobin Yvon-Horiba) was employed within $0 \cdot 5-3.0 \mathrm{eV}$ in steps of $0.05 \mathrm{eV}$ in ambient air at an angle of incidence of $65^{\circ}$. In measurements, the samples were placed one by one on the stage and conventional ellipsometric angles ( $\Psi$ and $\Delta$ ) were then obtained. Since ellipsometry does not provide direct information about the dielectric properties of a sample, pseudo-dielectric functions were 
extracted from the ellipsometry-measured $\Psi$ and $\Delta$ values by using the equation $\langle\varepsilon\rangle=\sin ^{2} \Theta+\sin ^{2} \Theta \tan ^{2} \Theta\left(1-\tan \Psi \mathrm{e}^{i \Delta} / 1+\right.$ $\left.\tan \Psi^{i \Delta}\right)^{2},{ }^{33}$ where $\Theta$ is the angle of incidence.

In Sers experiments, a DeltaNu Examiner Raman microscopy system equipped with a $785 \mathrm{~nm}$ laser source, a motorized microscope stage sample holder, and a cooled charge coupled device detector was employed in the range $200-2000 \mathrm{~cm}^{-1}$. The related Raman instrument parameters were as follows: $\times 20$ objective, $3 \mu \mathrm{m}$ spot size, $30 \mathrm{~s}$ acquisition time and $150 \mathrm{~mW}$ laser power. For all measurements, baseline correction was carried out. The Sers performances of samples were investigated using methylene blue (MB) as a Raman reporter molecule. In a typical experiment, $5 \mu \mathrm{l}$ of a $1 \mathrm{mM}$ aqueous solution of MB was dropped onto the fabricated samples and the samples were kept in a hood until dry. The drying procedure led to coin-shaped Raman reporter molecule sizes of $\sim 3.5 \pm 0.5 \mathrm{~mm}$ onto the fabricated surfaces. For each sample, at least ten Raman spectra were collected from the different spots of the sample.

Cell viability was determined by cell adhesion experiments and an indirect cytotoxicity MTT test using Saos-2 human osteosarcoma cells (Saos-2/An1, Foot and Mouth Disease Institute, Ankara, Turkey). Substrates were sized at $1.5 \times 1.5 \mathrm{~mm}$. All substrates were sterilized by autoclaving and were then rinsed with phosphate-buffered saline (PBS) before seeding the cells. In brief, the cells were cultured on the substrates in Dulbecco's modified Eagle medium supplemented with $1 \%$ volume/volume $(\mathrm{v} / \mathrm{v})$ penicillin/streptomycin and $10 \%(\mathrm{v} / \mathrm{v})$ fetal bovine serum. Cell suspensions $(50 \mu \mathrm{l})$ at a density of $1 \times 10^{5}$ cells $/ \mathrm{m}^{2}$ were inoculated into each well of a 24-multiwell plate containing the samples (unheated and heated blank TiNRs and gold-coated TiNR surfaces). The samples were incubated at $37^{\circ} \mathrm{C}$ in a humidified atmosphere of $5 \%(\mathrm{v} / \mathrm{v})$ carbon dioxide $\left(\mathrm{CO}_{2}\right)$ in air for $72 \mathrm{~h}$, and the culture medium was renewed once in two days. ${ }^{34,35}$ For cell viability, after the time intervals, samples were transferred to another 96-well plate after being washed twice with PBS. Then, $100 \mu \mathrm{l}$ of fresh culture medium and $10 \mu \mathrm{l}$ of the MTT solution were added to each well for $4 \mathrm{~h}$ at $37^{\circ} \mathrm{C}$. After the incubation, the mediums were aspirated and $100 \mu 1$ isopropanol:100 $\mu 1$ dimethyl sulfoxide was added into well plates for colorimetric measurement of the formazan dye on a spectrometer at $570 \mathrm{~nm}$ with an enzyme linked immunosorbent assay test kit in a SpectraMax 340PC microplate reader.

For the adhesion test, after $48 \mathrm{~h}$, the cell culture medium was aspirated from the wells and the substrates were gently rinsed with PBS to remove any non-adherent cells. Afterward, the adhered cells were then fixed with $2 \cdot 5 \%(\mathrm{v} / \mathrm{v})$ glutaraldehyde solution for $30 \mathrm{~min}$ and then washed with PBS gently and then washed with different concentrations of ethanol (30, 50, 70, 90 and $100 \%$ ) for $2 \mathrm{~min}$. For the last step of fixation, substrates with cells were dried out by using hexamethyldisilazane for 5 min. $^{36}$ Dried substrates were coated with gold palladium (AuPd) and characterized by SEM.
Statistical analyses were expressed as mean \pm standard deviation for three independent experiments. One way analysis of variance was used to test for significance using the Origin 8 software package (OriginLab, Northampton, Massachusetts, USA). Differences were considered statistically significant for $p<0 \cdot 05$.

\section{Results and discussion}

\subsection{Surface characterization with SEM and XPS}

The deposition of plasmonic nanostructures onto the support materials with $3 \mathrm{D}$ morphologies is a challenging issue due to the limited diffusion of metal ions into the support materials, the lack of large-area homogeneity and unwanted aggregation of nanostructures..$^{37,38}$ In this context, solid-state dewetting of plasmonic thin films offers unique advantages for the creation of plasmonic nanostructure arrays over a substrate material with 3D morphology. The average size and separation of plasmonic nanostructures can easily be manipulated by controlling the initial thickness of a thin metal film and the annealing temperature. Based on the aforementioned premises, the authors fabricated goldnanostructure-decorated $3 \mathrm{D}$ platforms based on the solid-state dewetting approach for practical Sers applications. To this end, 3D TiNRs were first fabricated on a silicon (001) substrate by way of the PVD-OAD technique using a $5^{\circ}$ deposition angle, an ultrafast deposition rate $(>30 \mathrm{~nm} / \mathrm{s})$ and a short source-substrate distance $(\sim 10 \mathrm{~cm})$ under vacuum $\left(\sim 10^{-6}\right.$ Torr $) .^{39}$ Figure 1(a) shows the SEM images of fabricated TiNRs at a certain deposition angle $\left(\alpha=5^{\circ}\right)$. It is obvious that closely packed and tilted TiNRs were successfully obtained along the substrate surface. The nanorod densities were analyzed using the ImageJ freeware and were found to be $9.4 \times$ $10^{8}$ nanorods $/ \mathrm{cm}^{2}$. The nanorod lengths and tilt angles were also calculated as $1.5 \pm 0.4 \mu \mathrm{m}$ and $80 \pm 2^{\circ}$, respectively.

After fabrication of 3D nanostructured TiNR arrays, they were coated with a thin film of gold with varying thicknesses $(5-30 \mathrm{~nm})$ through PVD (see Section 2 details). Note, as evidenced from SEM characterizations, that the 3D nanostructured morphology of the TiNR arrays was preserved after gold deposition (Figure 1(b)). Chemical characterization of TiNR arrays before and after gold deposition was performed by XPS (Figure 2). For pristine TiNR arrays, the binding energies of titanium (Ti) $2 \mathrm{~s}$, titanium $2 \mathrm{p}^{1}-2 \mathrm{p}^{3}$, titanium $3 \mathrm{~s}$, titanium $3 \mathrm{p}$ and oxygen (O) $1 \mathrm{~s}$ peaks were 561,461 and $456,529,59$ and $34 \mathrm{eV}$, respectively, corresponding to characteristic regions of a vapordeposited titanium film. The strong carbon (C) 1 s peak at $284 \mathrm{eV}$ was probably due to contamination of the films during operation. Following the gold thin-film deposition, most of the characteristic titanium peaks disappeared but there were strong gold peaks at $541 \mathrm{eV}$ for gold $4 \mathrm{p}^{3}, 351 \mathrm{eV}$ for gold $4 \mathrm{~d}^{3}, 330 \mathrm{eV}$ for gold $4 \mathrm{~d}^{5}$, $85 \mathrm{eV}$ for gold $4 \mathrm{f}^{5}$ and $80 \mathrm{eV}$ for gold $4 \mathrm{f}^{7}$, confirming the deposition of gold thin films on TiNRs.

To fabricate nanostructured gold with varying shapes and sizes on TiNRs, the samples were thermally annealed in a tube furnace at different temperatures ranging from 450 to $750^{\circ} \mathrm{C}$. After 


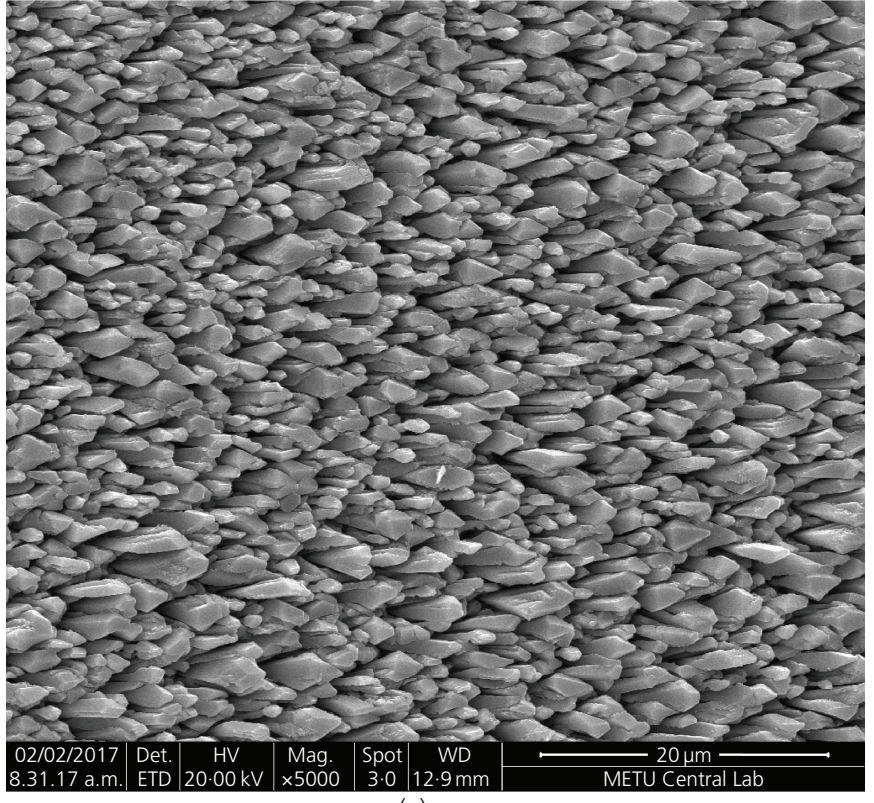

(a)

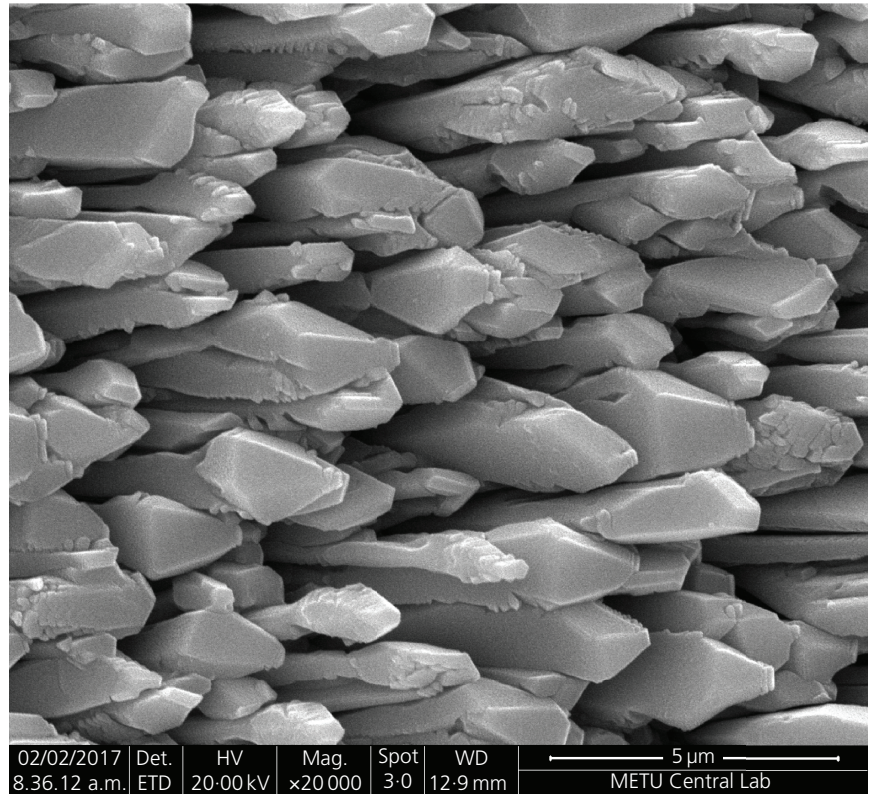

(b)

Figure 1. Top-view SEM images of (a) fabricated TiNRs and (b) gold-thin-film-deposited TiNR arrays (the gold film thickness is $30 \mathrm{~nm}$ )

annealing, the samples were cooled for $\sim 60$ min before removing them from the furnace to avoid a sudden decrease in temperature. Figure 3 shows the SEM images of resultant morphologies after thermal annealing of gold thin films deposited on TiNR arrays. It is obvious that, as a result of thermal annealing, gold thin films on TiNR arrays turn into nanoislands with promiscuous shapes and sizes on the TiNRs due to the mobility of gold atoms in the film. ${ }^{40}$ In this process, it should be noted that both the gold film thickness and annealing temperature determine the structural parameters of the gold nanoislands (e.g. their size, spacing and density). ${ }^{41-43}$ Since dewetting depends on atomic transport, the rate of dewetting is dependent on temperature strongly. At the beginning, dewetting was observed at $450^{\circ} \mathrm{C}$ annealing temperature, and then the thin gold film turned into a partially connected island film. After thermal treatment, drastic shape changes were seen according to the thickness of the gold film. A $30 \mathrm{~nm}$ initial gold film thickness on TiNRs was transformed into a discontinuous shape upon hole nucleation and eventually disintegrated into isolated sphere-shaped islands at a temperature of $450^{\circ} \mathrm{C}$. The dewetting of the gold thin film was directed by the surface diffusion to reduce the surface area in order to minimize the total energy of the system.

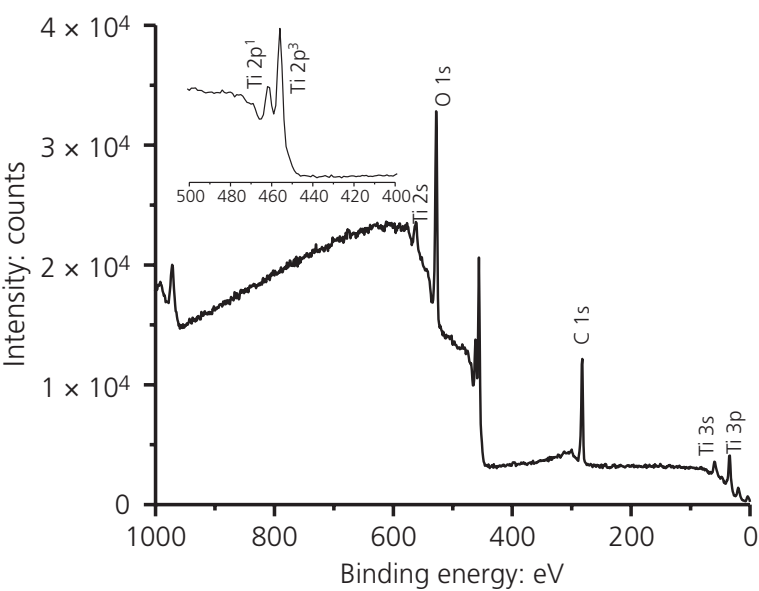

(a)

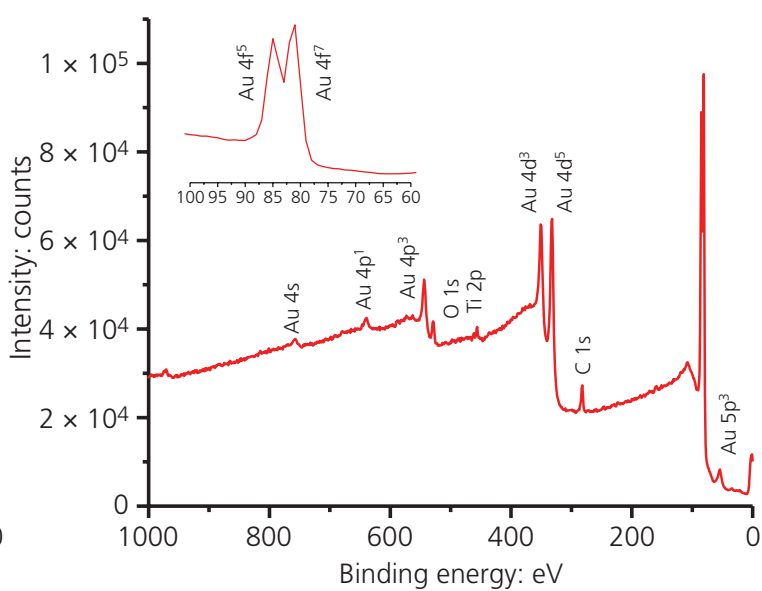

(b)

Figure 2. (a) XPS spectrum of pristine TiNR arrays; inset: XPS spectrum of titanium $2 p^{1}$ and titanium $2 p^{3}$. (b) XPS spectrum of gold-thinfilm-deposited TiNR arrays; inset: XPS spectrum of gold $4 f^{5}$ and gold $4 f^{7}$ (the gold film thickness is $30 \mathrm{~nm}$ ) 


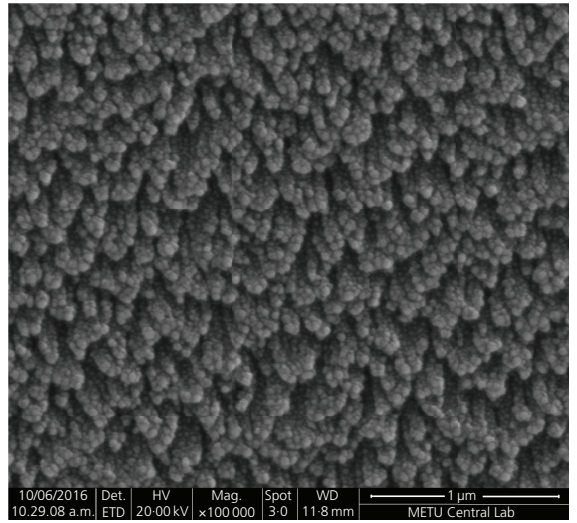

(a)

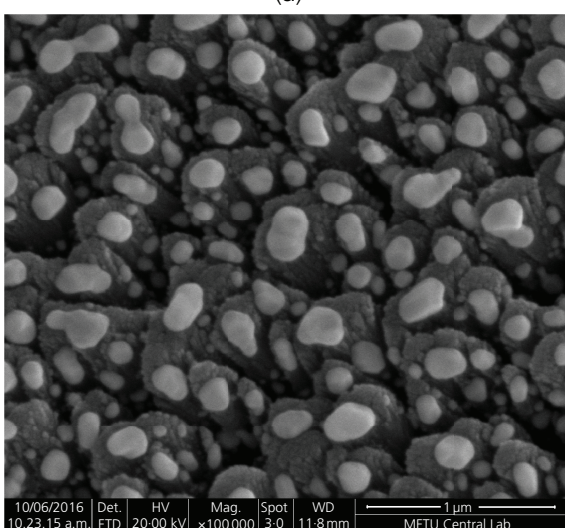

(d)

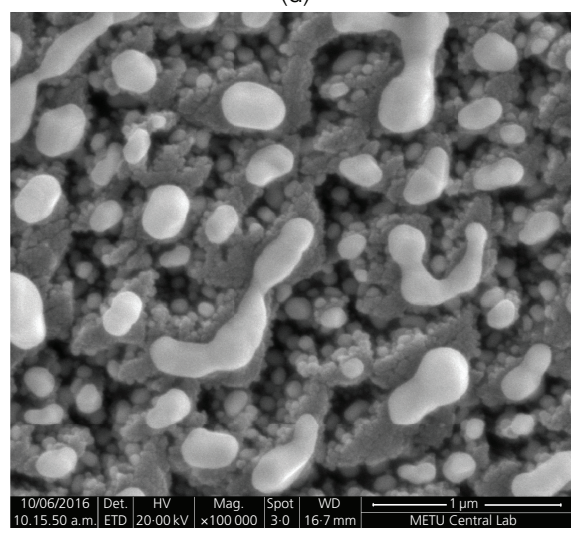

(g)

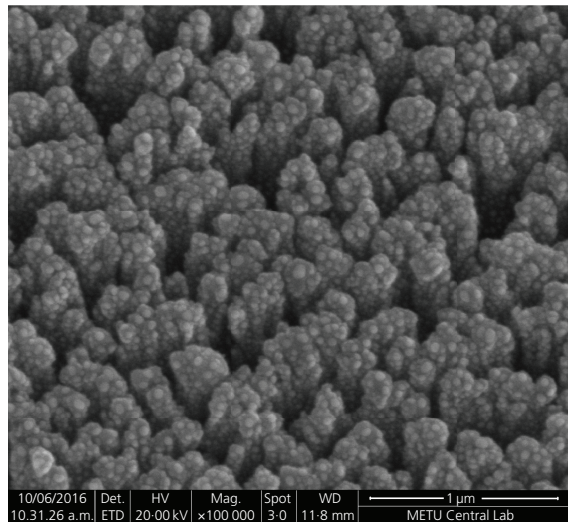

(b)

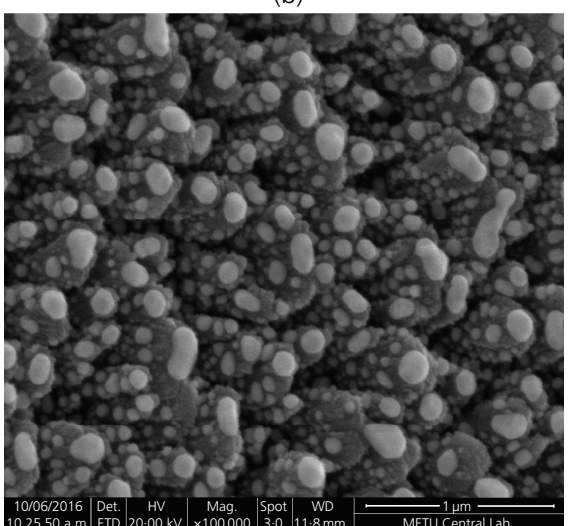

(e)

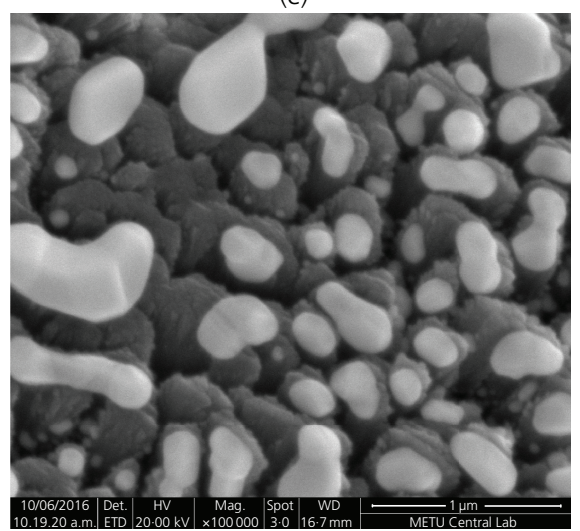

(h)

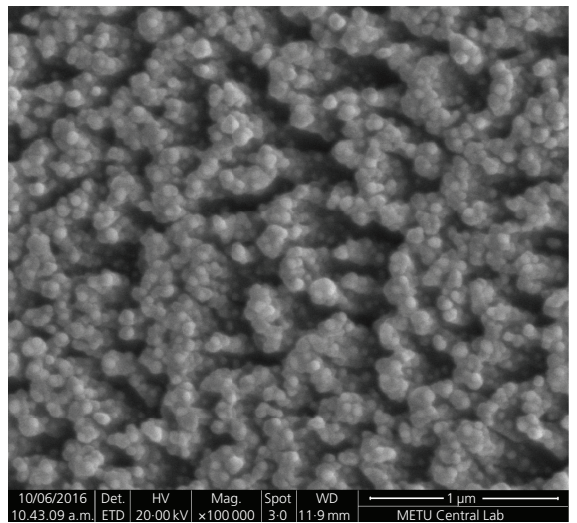

(c)

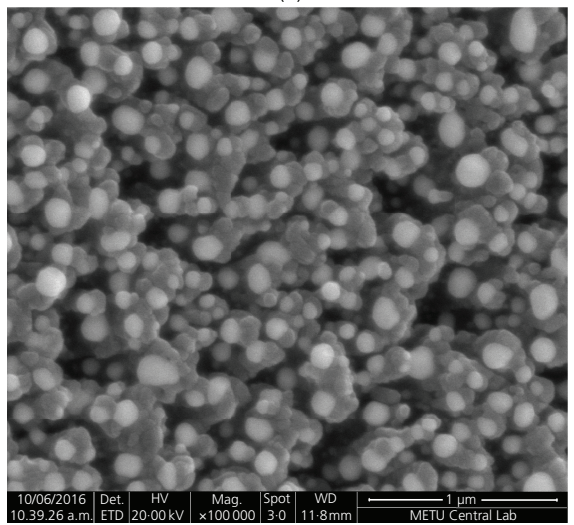

(f)

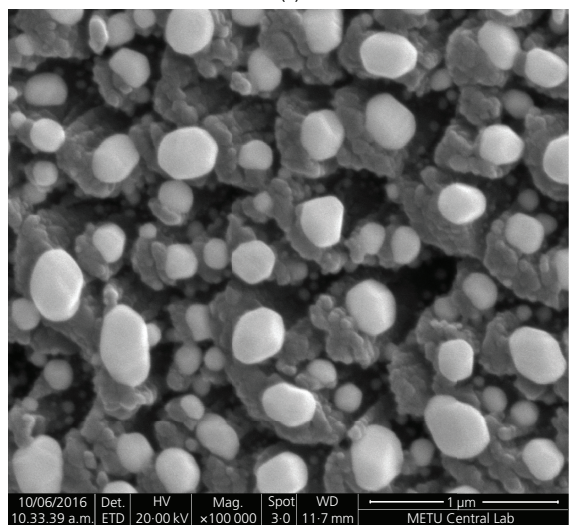

(i)

Figure 3. Top-view SEM images of thermally annealed gold-thin-film-deposited TiNR arrays for (a-c) 5, (d-f) 15 and (g-i) $30 \mathrm{~nm}$ gold film thicknesses at varying annealing temperatures

As the film becomes thinner, its surface-to-volume ratio becomes bigger, and this causes the activation energy of the film to decrease for metal atom surface mobility. Because of this, the surface energy rises dramatically when the film thickness declines. For this reason, dewetting can be seen at temperatures below the melting point of the film. ${ }^{44}$

As can be seen from the Figure 3, since surface diffusion was faster in the thinner films, wormlike gold islands were not formed during dewetting. ${ }^{45}$ This phenomenon also affected the nanoisland densities. In the case of the $30 \mathrm{~nm}$ initial gold thickness, gold nanoislands were formed as larger in size and lower density. While initial thickness of gold film on TiNRs was decreased from $30 \mathrm{~nm}$ to 15 and $5 \mathrm{~nm}$ thickness, nanoislands turned into round shaped particles, became smaller in size and higher in density.

\subsection{Spectroscopic ellipsometry}

To evaluate the plasmonic properties of the fabricated films, the authors employed spectroscopic ellipsometry. Figures 4(a)-4(c) show the amplitude $(\Psi)$ spectra of gold-thin-film-deposited TiNR 


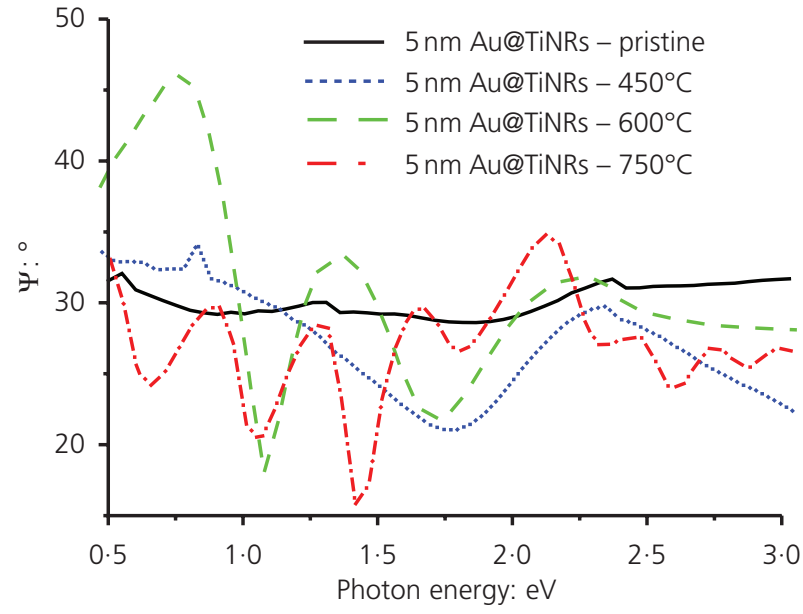

(a)

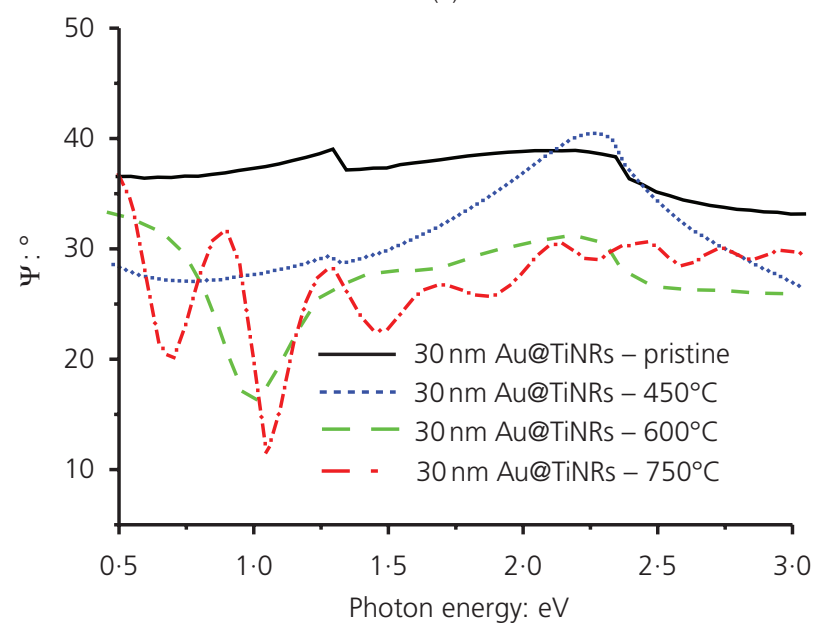

(c)

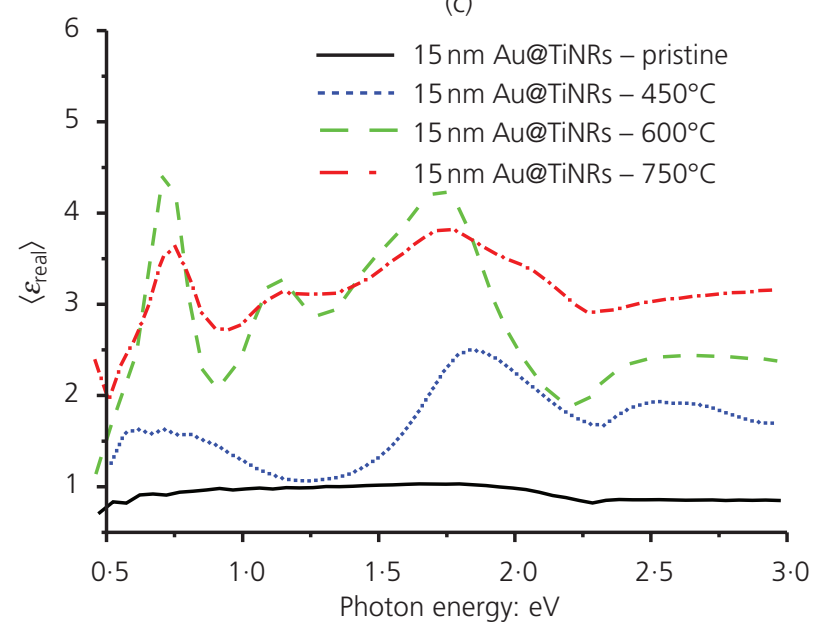

(e)

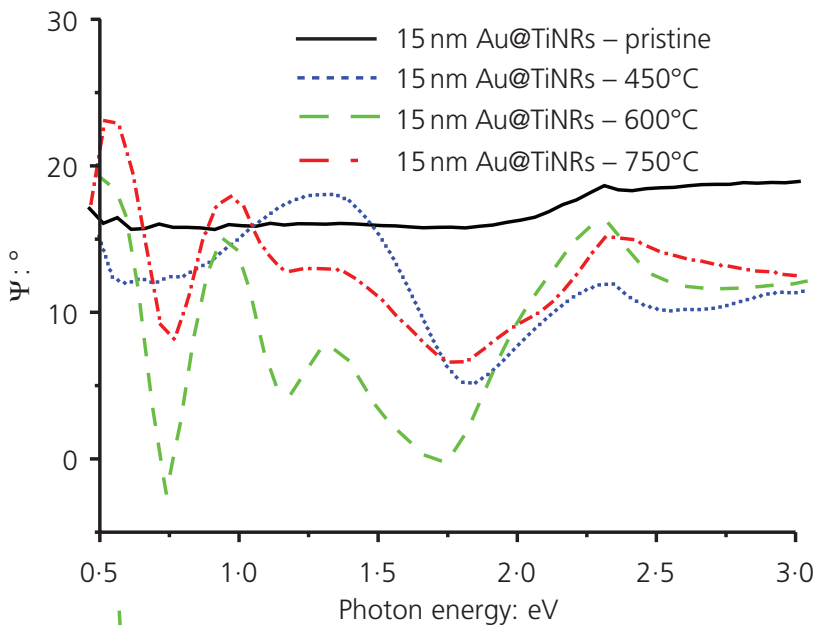

(b)

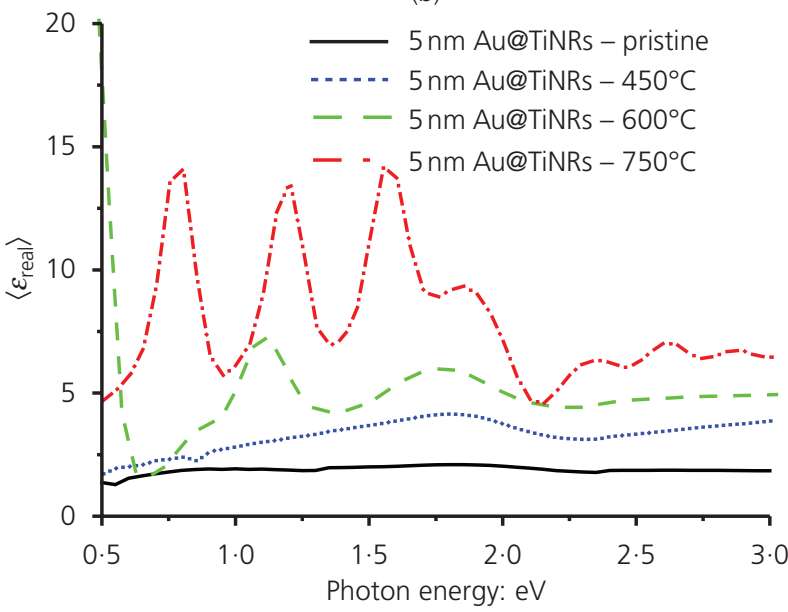

(d)

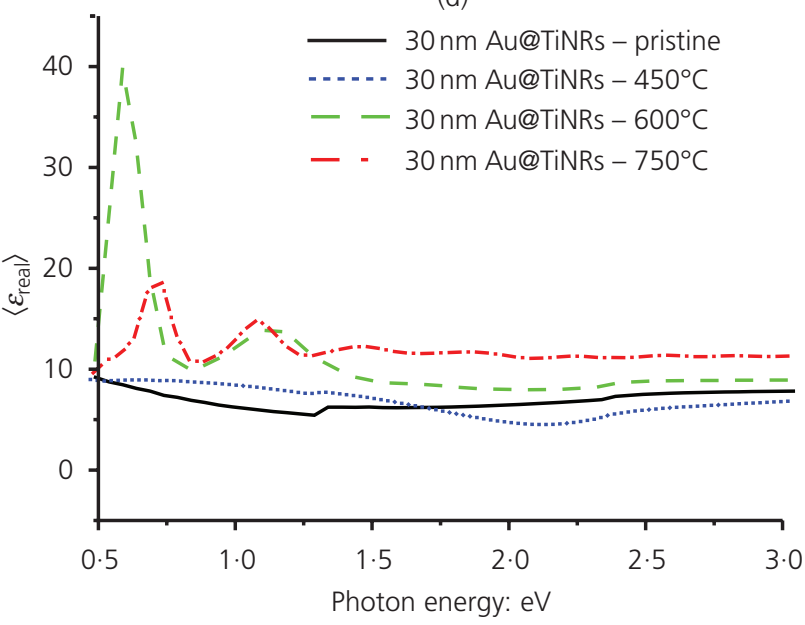

(f)

Figure 4. The variations in $(a-c)$ the amplitude $(\Psi)$ spectra and $(d-f)$ the real part of the pseudo-dielectric functions $\left(\varepsilon_{\text {real }}\right)$ for gold-thinfilm-deposited TiNR arrays with different gold initial thicknesses before and after thermal annealing

arrays before and after thermal annealing. As it can been seen from Figures 4(a)-4(c), a notable plasmonic behavior can be observed for the films with different initial gold thicknesses before thermal annealing. After the thermal annealing process, obvious plasmonic signals depending on both the initial gold film thickness and annealing temperature were identified. For the case 
of the $450^{\circ} \mathrm{C}$ annealing temperature, the amplitude spectra revealed a broad dip at $\approx 1.9 \mathrm{eV}(656 \mathrm{~nm})$ for the $5 \mathrm{~nm}$ gold initial thickness, at $\approx 1.9 \mathrm{eV}(639 \mathrm{~nm})$ for the $15 \mathrm{~nm}$ gold initial thickness and at $\approx 1.4 \mathrm{eV}$ $(861 \mathrm{~nm})$ for the $30 \mathrm{~nm}$ gold initial thickness. When the annealing temperature was increased from 450 to $600^{\circ} \mathrm{C}$, the gold-deposited TiNRs reveal a different plasmonic behavior depending on their initial gold thicknesses. For the $5 \mathrm{~nm}$ gold initial thickness, the amplitude

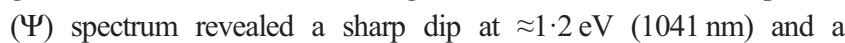
relatively broader dip at $\approx 1.8 \mathrm{eV}(673 \mathrm{~nm})$ (Figure $4(\mathrm{a})$ ). At this annealing temperature $\left(600^{\circ} \mathrm{C}\right)$, when the initial gold thickness on TiNR arrays was increased from 5 to $15 \mathrm{~nm}$, a new sharp dip at $\approx 0.8 \mathrm{eV}(1476 \mathrm{~nm})$ was identified in addition to dips at $\approx 1.3 \mathrm{eV}$ $(961 \mathrm{~nm})$ and $\approx 1.8 \mathrm{eV}(673 \mathrm{~nm})$ (Figure 4(b)). As for the $30 \mathrm{~nm}$ initial gold thickness, interestingly, only one dip at $\approx 1 \cdot 1 \mathrm{eV}(1137 \mathrm{~nm})$ was observed (Figure 4(c)). The shift in the amplitude spectra and changes in the broadening of the dips was possibly due to the electromagnetic coupling between formed gold nanostructures. ${ }^{46}$ When the annealing temperature of films was further increased from 600 to $750^{\circ} \mathrm{C}$, the authors observed a number of dips at different photon energies due to the formation of dense gold nanostructures (mostly particulate shape) with varying sizes on TiNRs. Similar results were also observed for the real part of the pseudo-dielectric function $\left(\varepsilon_{\text {real }}\right)$ of films (Figures $4(\mathrm{~d})-4(\mathrm{f})$ ). In those cases, the real part of pseudo-dielectric functions increased through the highly polarizable free charge carriers due to electron confinement after thermal annealing of gold thin films. ${ }^{47}$ It is clear that the plasmonic behaviors of platforms may be easily manipulated by gold film thickness on TiNR arrays and thermal annealing temperature.

\subsection{Raman spectroscopy}

The authors investigated the Sers performances of the fabricated platforms with gold nanostructures in varying sizes and shapes. It is reasonable to expect high local electromagnetic field enhancement from the 3D morphology of platforms and dense plasmonic gold nanostructures if the distance between two neighboring gold nanostructures is shorter than the nanostructure diameter. ${ }^{48,49}$ In this respect, an aqueous solution of $\mathrm{MB}\left(5 \mu \mathrm{l}, 1 \times 10^{-3} \mathrm{M}\right)$, which was chosen as a Raman reporter, was deposited on the fabricated films. First, the authors analyzed the Sers performance of pristine TiNR arrays before gold thin-film deposition, which, as expected, did not yield any Raman signal (data not shown). This result is attributed to the absence of plasmonic metal to create electromagnetic enhancement and unfavorable energy levels to lead to the chemical enhancement mechanism. ${ }^{50}$ However, when dewetted samples with gold nanoislands were employed, well defined and precise Sers signals were achieved with acceptable signal-to-noise ratios for all samples (Figure 5). The most prominent peaks in the spectra were found at $1622 \mathrm{~cm}^{-1}(v(\mathrm{C}-\mathrm{C})$ ring stretches $), 1399 / 1434 \mathrm{~cm}^{-1}$ $\left(\nu(\mathrm{C}-\mathrm{N})\right.$ symmetric and asymmetric stretches) and $450 \mathrm{~cm}^{-1}$ $(\delta(\mathrm{C}-\mathrm{N}-\mathrm{C})$ skeletal deformation mode) consistent with the authors' earlier reports. ${ }^{39,51,52}$

To quantify and compare the Sers performances of samples, the authors also calculated the enhancement factors (EFs) using the most prominent peak at $1622 \mathrm{~cm}^{-1}$ through the given formula ${ }^{52}$

$$
\mathrm{EF}=\left(N_{\text {reference }} \times I_{\text {Sers platform }(n)}\right) /\left(N_{\text {Sers platform }(n)} \times I_{\text {reference }}\right)
$$

1.

where $I_{\text {reference }}$ and $I_{\text {Sers platform }(n)}$ are the Raman intensities of MB on a silicon wafer and the adsorbed $\mathrm{MB}$ on sample (n), respectively, and $N_{\text {reference }}$ and $N_{\text {Sers platform(n) }}$ are the numbers of MB molecules for the reference sample and sample (n), respectively. Accordingly, the highest EFs are calculated to be 55

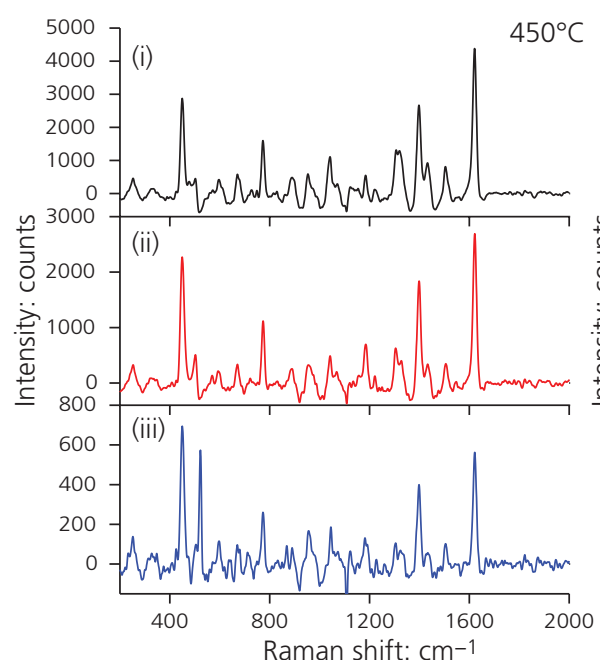

(a)

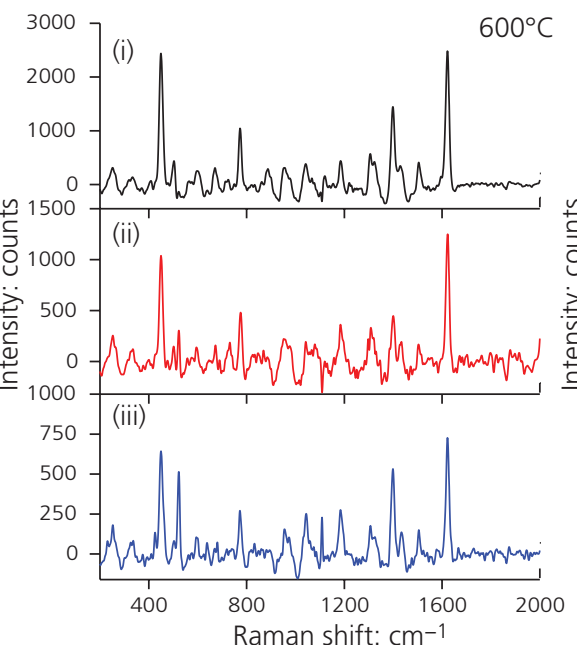

(b)

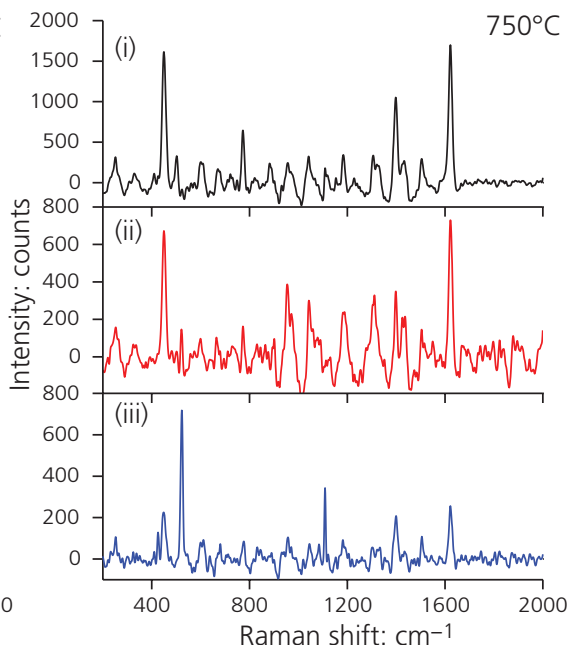

(c)

Figure 5. Representative Sers spectra of thermally annealed gold-thin-film-deposited TiNR arrays for (a) 450 , (b) 600 and (c) $750^{\circ} \mathrm{C}$ at varying annealing temperatures. (i) 30, (ii) 15 and (iii) $5 \mathrm{~nm}$ gold film thicknesses; $1 \mathrm{mM} \mathrm{MB} \mathrm{(3 \mu l)}$ 
for gold-30nm@TiNRs $\left(450^{\circ} \mathrm{C}\right), 31$ for gold-30 nm@TiNRs $\left(600^{\circ} \mathrm{C}\right)$ and 22 for gold $-30 \mathrm{~nm} @$ TiNRs $\left(750^{\circ} \mathrm{C}\right)$. For all cases, these enhancements in Sers signals mainly originated from the electromagnetic enhancement mechanism. The unique 3D morphology of TiNR arrays decorated with gold nanoislands can generate hot spots with a high electric field enhancement as a result of tip focusing, cavity resonances and antenna effects. ${ }^{53,54}$ As shown in Figure 5, the higher Sers peak intensity and EF obtained for gold-30 nm@TiNRs $\left(450^{\circ} \mathrm{C}\right)$, compared with other samples, might be due to the spacing between gold nanoislands and the density of gold nanoislands on TiNRs.

\subsection{In vitro cytotoxicity}

Finally, the cytocompatibility of the surfaces was evaluated by the MTT assay and adhesion test to understand the influence of blank and gold-coated, heated and unheated TiNR film surfaces on the viability of Saos-2 human osteosarcoma cells. Figure 6 shows the viability of cells adhered to the unheated and heated TiNR films after $72 \mathrm{~h}$ of incubation. Cell response may vary with the time on $3 \mathrm{D}$ platforms ${ }^{55}$ which need for sufficiently lengthened culture time to maintain the long-term cell behavior in medical applications, such as implants. ${ }^{56}$ For this reason, $72 \mathrm{~h}$ was selected as the incubation time to observe cell proliferation and the cytotoxicity experiment clearly. Viability was greater for cells grown on the heated gold-coated TiNR films than for those grown on the unheated TiNR films as can be seen in Figure 6(a)) after $72 \mathrm{~h}$ incubation. The results show that the heated gold-coated TiNR films provide better potential for cell behavior to some degree. This may indicate that a stronger ability for surface topography and chemistry is important for cell growth. ${ }^{57}$ For the uncoated TiNR films, annealing at $450^{\circ} \mathrm{C}$ shows better compatibility for cell growth, as can be seen in Figure 6(b), suggesting that the micro-/ nano-structure of the TiNR film heated at $450^{\circ} \mathrm{C}$ is more effective for cell growth than the other heated surfaces.
Not only the situation of individual cells, but also the number of cells both contribute to total cytocompatibility. Here, an increase in cell number was responsible for cellular metabolism. The role of nanotopography in promoting cell proliferation has been confirmed by other studies. ${ }^{58}$ Huang et al. ${ }^{59}$ conducted a study to view the cell viability and proliferation of Saos- 2 cells cultured on nanocrater and nanoleaf structures on micro-/nano-titanium surfaces. They found that the nanoleaf surface supported cell proliferation, while the nanoplate surface slowed down the proliferation. In another study, osteoblastlike Saos- 2 cells were cultured on both unmodified and anodized titanium surfaces for cytocompatibility tests. Results showed that cell adhesion and proliferation rates increased for all anodized surfaces compared to those for unmodified surfaces. ${ }^{60}$

\subsection{Cell adhesion}

Cell adhesion was greater on all heated and unheated TiNR and gold-coated TiNR films, as seen in SEM images of Figure 7 after $48 \mathrm{~h}$ incubation. It was observed that surfaces incubated with Saos-2 human osteosarcoma cells formed a layer of cells covering the entire TiNR surface. It is possible to see from the SEM images that Saos-2 osteosarcoma cells exhibited well-spread and prolonged morphology on modified titanium surfaces. Moreover, the presence of cells that had acquired spherical morphology was also observed. Cells with spherical morphology are cells that have not yet attached to the surface because of the cell density. This may show that the micron-sized porous structure of the TiNR film and the roughness of gold nanoislands on the TiNR film enhance the cell attachment on modified surfaces, facilitate adhesion and provide a suitable surface to grow. The surface characteristics of modified surfaces have importance in the interaction of modified surfaces with human osteogenic cells (Saos-2).

Improvement of cell adhesion on different nanotextures or micro-/ nano-structures has been widely reported. Kaga et al. ${ }^{61}$ fabricated

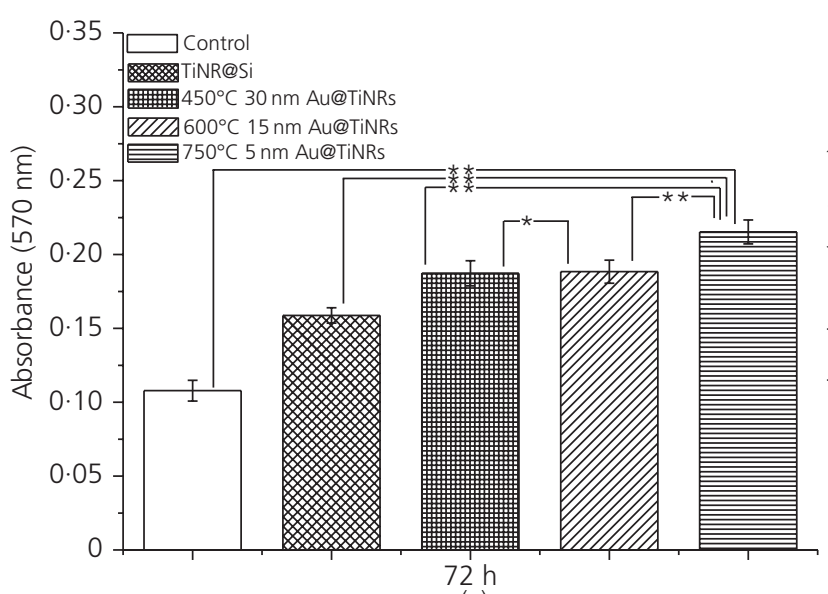

(a)

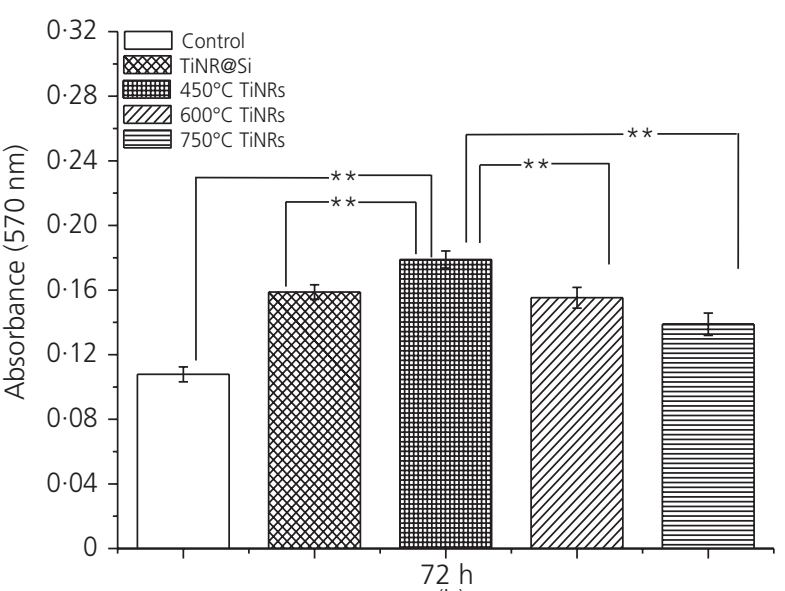

(b)

Figure 6. MTT assay of Saos-2 cells cultured onto nanorod films after $72 \mathrm{~h}$ incubation. Absorbance (570 nm) onto (a) gold-coated TiNR substrates annealed at different temperatures and (b) TiNR substrates annealed at different temperatures as a function of time. Data were determined from three independent cultures and are expressed as mean \pm standard deviation $\left({ }^{*} p>0.05,{ }^{* *} p<0.05\right)$ 


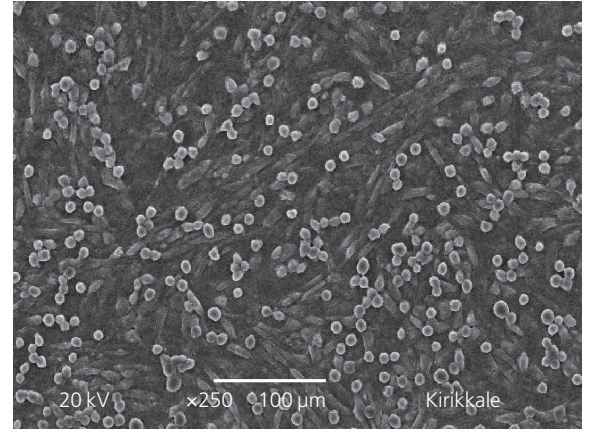

(a)

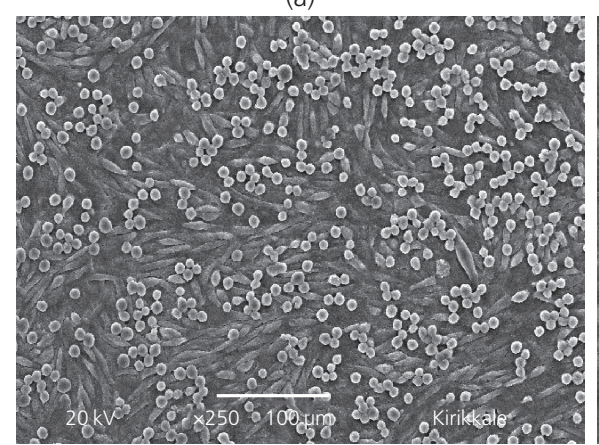

(d)

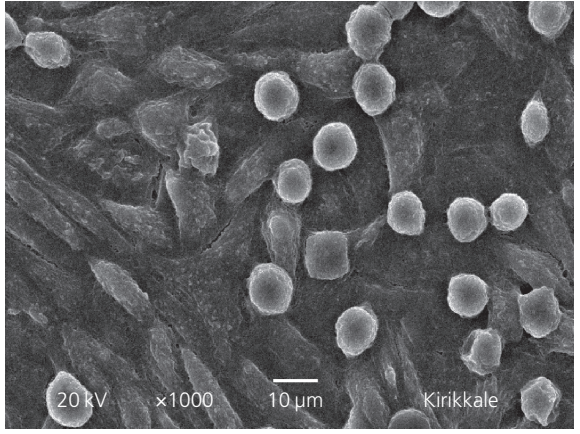

(b)

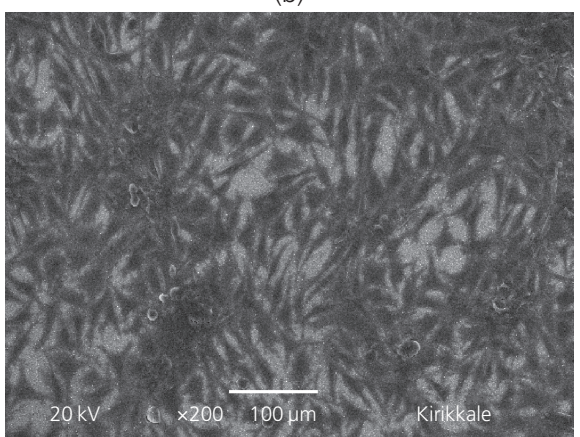

(e)

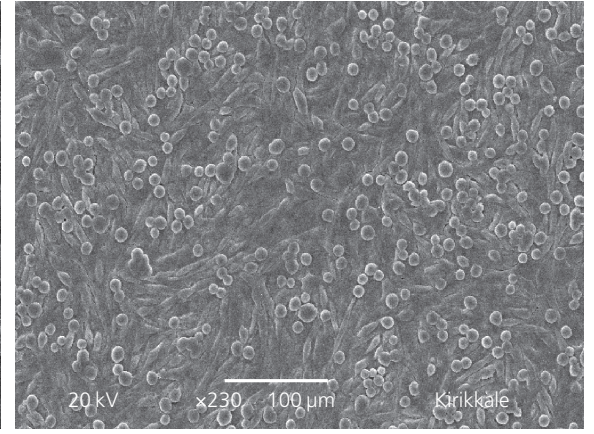

(c)

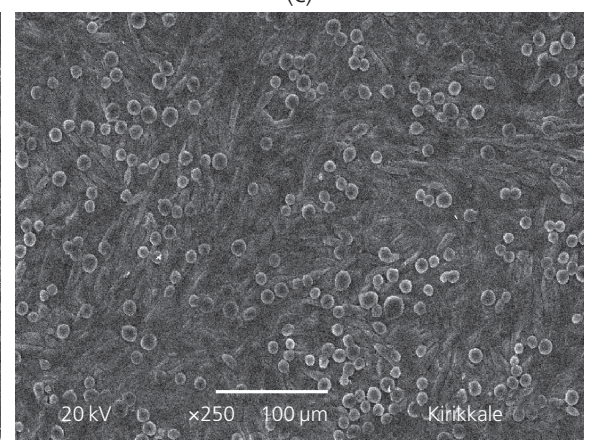

(f)

Figure 7. SEM images of Saos-2 osteosarcoma cells grown onto (a) TiNRs ( $\times 250)$, (b) TiNRs $(\times 1000)$, (c) annealed TiNRs at $450^{\circ} \mathrm{C}$, (d) annealed $30 \mathrm{~nm}$ gold@TiNRs at $450^{\circ} \mathrm{C}$, (e) annealed $15 \mathrm{~nm}$ gold@TiNRs at $600^{\circ} \mathrm{C}$ and (f) annealed $5 \mathrm{~nm}$ gold@TiNRs at $750^{\circ} \mathrm{C}$ after culturing for $48 \mathrm{~h}$

a sheet of micro-/nano-grooves and pillars coated with titanium (titanium sheet). Grooves and pillar shapes of $500 \mathrm{~nm}, 1 \mu \mathrm{m}$ and $2 \mu \mathrm{m}$ were made by the nanoimprinting method. A cell adhesion and proliferation test was carried out with Saos-2 cells on the patterned titanium sheets. Results showed that the number of cells attached to titanium sheets with grooves of $500 \mathrm{~nm}$ and $1 \mu \mathrm{m}$ was significantly higher than those on smooth titanium sheets and on grooves of $2 \mu \mathrm{m}$ after incubation for 1 and $24 \mathrm{~h}$. The filopodia of cells on $500 \mathrm{~nm}$ grooves extended from the cell periphery into the inner groove and were oriented in a direction parallel to the grooves. The grooves and pillars provided a grip for initial adhesion. ${ }^{61}$ Choi et al. ${ }^{62}$ showed that the relationship between the height of a nanosized sharp tip (heights: 50-100, 200-300 and $500-600 \mathrm{~nm}$; width: $230 \mathrm{~nm}$ ) and cellular activities informs considerably greater cell proliferation at low heights $(50-100 \mathrm{~nm})$ than at high heights $(500-600 \mathrm{~nm})$. Investigation of cell morphology has demonstrated a high degree of cell extension with pillar-shaped patterns. ${ }^{62}$ Human osteoblasts have shown interesting features, including long filopodia extensions and lamellipodia formation, in nanopillar structures. ${ }^{63}$ The authors' nanopatterned surfaces and cells can be connected, forming focal adhesions at the points of pillar structures, ${ }^{64,65}$ and the different shapes and sizes of nanopatterns can produce a range of focal adhesions. ${ }^{66}$ In addition, the shape, width and size of diverse nanoscale patterns can markedly influence cell adhesion, morphology, differentiation and stretching.

\section{Conclusion}

The authors have demonstrated a simple and versatile approach to fabricating active platforms based on 3D TiNR arrays with plasmonic (gold) nanoislands for Sers-based sensor applications and evaluated those platforms for cell viability. The authors' approach mainly involved OAD of TiNRs and dewetting of gold thin films on TiNRs. Owing to the controllable morphology and density of gold nanoislands achieved by way of a simple dewetting approach on TiNR arrays, the plasmonic behaviors and Sers performances of platforms were manipulated. Cell viability studies showed that heated gold-coated TiNR films provided better surfaces for cytocompatibility and cell growth. Taken together, the authors' results clearly demonstrate that 3D nanostructured morphology hold great promise for the fabrication of 3D Sers and tissue engineering platforms that can behave as an extracellular matrix that supports cells and provides guided cell function. Three-dimensional nanostructured platforms organize cell-cell interactions, and, through this, bone tissue response can be modulated between tissue and the implant. Moreover, by changing the morphology of the 3D platforms (e.g. wire, helical or chevron) and metallic thin-film type (e.g. silver $(\mathrm{Ag})$ or copper $(\mathrm{Cu})$ ) used, the Sers abilities of the resulting platforms can be varied to actualize further applications.

\section{Acknowledgements}

The authors thank Dr Gökhan Demirel for the helpful discussions and support with equipments and protocols. This work was 
partially supported by the Scientific and Technological Research Council of Turkey (Project/Grand Number: 1130864) and E. P. also acknowledges support from Turkish Academy of Sciences.

\section{REFERENCES}

1. Yang $S$, Cao B, Kong L and Wang Z (2011) Template-directed dewetting of a gold membrane to fabricate highly SERS-active substrates. Journal of Materials Chemistry 21(36): 14031-14035.

2. Ryzhkov NV, Brezhneva N and Skorb EV (2019) Feedback mechanisms at inorganic/polyelectrolyte multilayers interfaces for applied materials. Surface Innovations 7(3-4): 145-167, https://doi.org/10.1680/jsuin.19.00006.

3. Rossnagel S (2003) Thin film deposition with physical vapor deposition and related technologies. Journal of Vacuum Science \& Technology A: Vacuum, Surfaces, and Films 21(5): S74-S87.

4. He Y, Zhang Z and Zhao Y (2008) Optical and photocatalytic properties of oblique angle deposited $\mathrm{TiO}_{2}$ nanorod array. Journal of Vacuum Science \& Technology B: Microelectronics and Nanometer Structures Processing, Measurement, and Phenomena 26(4): 1350-1358.

5. Jones MR, Osberg KD, Macfarlane RJ, Langille MR and Mirkin CA (2011) Templated techniques for the synthesis and assembly of plasmonic nanostructures. Chemical Reviews 111(6): 3736-3827.

6. Zhan P, Dutta PK, Wang P et al. (2017) Reconfigurable threedimensional gold nanorod plasmonic nanostructures organized on DNA origami tripod. ACS Nano 11(2): 1172-1179.

7. Bhat R, Sell S, Wagner R et al. (2010) The Janus-SAM approach for the flexible functionalization of gold and titanium oxide surfaces. Small 6(3): 465-470.

8. Dhawan A, Du Y, Batchelor D et al. (2011) Hybrid top-down and bottom-up fabrication approach for wafer-scale plasmonic nanoplatforms. Small 7(6): 727-731.

9. Biswas A, Bayer IS, Biris AS et al. (2012) Advances in top-down and bottom-up surface nanofabrication: techniques, applications \& future prospects. Advances in Colloid and Interface Science 170(1-2): 2-27.

10. Nugroho FA, landolo B, Wagner JB and Langhammer C (2016) Bottom-up nanofabrication of supported noble metal alloy nanoparticle arrays for plasmonics. ACS Nano 10(2): 2871-2879.

11. Shtein $Z$ and Shoseyov O (2017) When bottom-up meets top-down. Proceedings of the National Academy of Sciences of the United States of America 114(3): 428-429.

12. Fantino $E$, Chiappone A, Calignano F et al. (2016) In situ thermal generation of silver nanoparticles in $3 \mathrm{D}$ printed polymeric structures. Materials 9(7): article 589

13. Sakai N, Fujiwara Y, Takahashi $Y$ and Tatsuma T (2009) Plasmonresonance-based generation of cathodic photocurrent at electrodeposited gold nanoparticles coated with $\mathrm{TiO}_{2}$ films. ChemPhysChem 10(5): 766-769.

14. Kim D, Giermann AL and Thompson CV (2009) Solid-state dewetting of patterned thin films. Applied Physics Letters 95(25): 251903.

15. Trautmann M, Cheynis F, Leroy F et al. (2017) Dewetting of patterned solid films: towards a predictive modelling approach. Applied Physics Letters 110(26): article 263105

16. Amram D, Klinger $L$ and Rabkin E (2012) Anisotropic hole growth during solid-state dewetting of single-crystal Au-Fe thin films. Acta Materialia 60(6-7): 3047-3056.

17. Leroy F, Cheynis F, Almadori Y et al. (2016) How to control solid state dewetting: a short review. Surface Science Reports 71(2): 391-409.

18. Zhao X, Lee UJ and Lee KH (2010) Dewetting behavior of Au films on porous substrates. Thin Solid Films 519(2): 706-713.

19. Drelich J and Marmur A (2014) Physics and applications of superhydrophobic and superhydrophilic surfaces and coatings. Surface Innovations 2(4): 211-227, https://doi.org/10.1680/si.13.00017.

20. Altomare M, Nguyen NT and Schmuki P (2016) Templated dewetting: designing entirely self-organized platforms for photocatalysis. Chemical Science 7(12): 6865-6886.
21. Han G, Wu Y, Luo P, Qiu J and Chong T (2003) Dewetting observations of ultrathin metallic films. Solid State Communications 126(8): 479-484.

22. Shin JW, Cho DH, Moon J et al. (2014) Random nano-structures as light extraction functionals for organic light-emitting diode applications. Organic Electronics 15(1): 196-202.

23. Lu L, Randjelovic I, Capek R et al. (2005) Controlled fabrication of gold-coated 3D ordered colloidal crystal films and their application in surface-enhanced Raman spectroscopy. Chemistry of Materials 17(23): 5731-5736

24. Popp J, Krafft C and Mayerhöfer T (2011) Modern Raman spectroscopy for biomedical applications: a variety of Raman spectroscopical techniques on the threshold of biomedical applications. Optik \& Photonik 6(4): 24-28.

25. Mallidis C, Sanchez V, Wistuba J et al. (2013) Raman microspectroscopy: shining a new light on reproductive medicine. Human Reproduction Update 20(3): 403-414.

26. Wang P, Liang O, Zhang W, Schroeder T and Xie YH (2013) Ultrasensitive graphene-plasmonic hybrid platform for label-free detection. Advanced Materials 25(35): 4918-4924.

27. Potara M, Boca S, Licarete E et al. (2013) Chitosan-coated triangular silver nanoparticles as a novel class of biocompatible, highly sensitive plasmonic platforms for intracellular SERS sensing and imaging. Nanoscale 5(13): 6013-6022.

28. Vasilev K, Poh Z, Kant K et al. (2010) Tailoring the surface functionalities of titania nanotube arrays. Biomaterials 31(3): 532-540.

29. Zhao L, Mei S, Chu PK, Zhang Y and Wu Z (2010) The influence of hierarchical hybrid micro/nano-textured titanium surface with titania nanotubes on osteoblast functions. Biomaterials 31(19): 5072-5082.

30. Kubo K, Tsukimura N, Iwasa F et al. (2009) Cellular behavior on $\mathrm{TiO}_{2}$ nanonodular structures in a micro-to-nanoscale hierarchy model. Biomaterials 30(29): 5319-5329.

31. Kafi MA, El-Said WA, Kim TH and Choi JW (2012) Cell adhesion, spreading, and proliferation on surface functionalized with RGD nanopillar arrays. Biomaterials 33(3): 731-739.

32. Zhong M-L, Li M and Li L-H (2015) Effects of different lengths of Ti nanorods topography on mesenchymal stem cell growth and proliferation. Journal of Nanoscience and Nanotechnology 15(5): 3893-3899.

33. Fujiwara H (2007) Spectroscopic Ellipsometry: Principles and Applications. Wiley, Chichester, UK.

34. Gao T, Aro HT, Ylänen H and Vuorio E (2001) Silica-based bioactive glasses modulate expression of bone morphogenetic protein-2 mRNA in Saos-2 osteoblasts in vitro. Biomaterials 22(12): $1475-1483$

35. Degasne I, Basle M, Demais V et al. (1999) Effects of roughness, fibronectin and vitronectin on attachment, spreading, and proliferation of human osteoblast-like cells (Saos-2) on titanium surfaces. Calcified Tissue International 64(6): 499-507.

36. Huang BQ and Yeung EC (2015) Chemical and physical fixation of cells and tissues: an overview. In Plant Microtechniques and Protocols (Yeung E, Stasolla C, Sumner M and Huang B (eds)). Springer, Cham, Switzerland, pp. 23-43.

37. Lopes WA and Jaeger HM (2001) Hierarchical self-assembly of metal nanostructures on diblock copolymer scaffolds. Nature 414(6865): 735-738.

38. Xi G, Ye J, Ma Q et al. (2012) In situ growth of metal particles on 3D urchin-like $\mathrm{WO}_{3}$ nanostructures. Journal of the American Chemical Society 134(15): 6508-6511

39. Yilmaz M, Senlik E, Biskin E et al. (2014) Combining 3-D plasmonic gold nanorod arrays with colloidal nanoparticles as a versatile concept for reliable, sensitive, and selective molecular detection by SERS. Physical Chemistry Chemical Physics 16(12): 5563-5570.

40. He JY, Lu JX, Dai N and Zhu DM (2012) Surface plasma resonance spectra of Au nanoparticles formed from dewetted thin films. Journal of Materials Science 47(2): 668-676. 
41. Schaub A, Slepička P, Kašpárková I et al. (2013) Gold nanolayer and nanocluster coatings induced by heat treatment and evaporation technique. Nanoscale Research Letters 8(1): article 249.

42. Leem J, Wang MC, Kang P and Nam S (2015) Mechanically selfassembled, three-dimensional graphene-gold hybrid nanostructures for advanced nanoplasmonic sensors. Nano letters 15(11): 7684-7690.

43. Furube A, Du L, Hara K, Katoh R and Tachiya M (2007) Ultrafast plasmon-induced electron transfer from gold nanodots into $\mathrm{TiO} 2$ nanoparticles. Journal of the American Chemical Society 129(48): 14852-14853.

44. Nguyen NT, Altomare M, Yoo JE, Taccardi N and Schmuki P (2016) Noble metals on anodic $\mathrm{TiO}_{2}$ nanotube mouths: thermal dewetting of minimal Pt co-catalyst loading leads to significantly enhanced photocatalytic $\mathrm{H}_{2}$ generation. Advanced Energy Materials 6(2): article 1501926.

45. Trice J, Thomas D, Favazza C, Sureshkumar R and Kalyanaraman R (2007) Pulsed-laser-induced dewetting in nanoscopic metal films: theory and experiments. Physical Review B 75(23): article 235439.

46. Beyene H, Weber J, Verheijen M, Van de Sanden M and Creatore M (2012) Real time in situ spectroscopic ellipsometry of the growth and plasmonic properties of $\mathrm{Au}$ nanoparticles on $\mathrm{SiO}_{2}$. Nano Research 5(8): $513-520$.

47. Yilmaz M, Kuloglu HB, Erdogan $\mathrm{H}$ et al. (2015) Light-driven unidirectional liquid motion on anisotropic gold nanorod arrays. Advanced Materials Interfaces 2(12): article 1500226.

48. Hu X, Cheng W, Wang T et al. (2005) Fabrication, characterization, and application in SERS of self-assembled polyelectrolyte-gold nanorod multilayered films. Journal of Physical Chemistry B 109(41): 19385-19389.

49. García-Vidal FJ and Pendry J (1996) Collective theory for surface enhanced Raman scattering. Physical Review Letters 77(6): 1163-1166.

50. Farzinpour P, Sundar A, Gilroy K et al. (2012) Altering the dewetting characteristics of ultrathin gold and silver films using a sacrificial antimony layer. Nanotechnology 23(49): 495604.

51. Yilmaz M, Ozdemir M, Erdogan $\mathrm{H}$ et al. (2015) Micro-/nanostructured highly crystalline organic semiconductor films for surface-enhanced Raman spectroscopy applications. Advanced Functional Materials 25(35): 5669-5676.

52. Akin MS, Yilmaz M, Babur E et al. (2014) Large area uniform deposition of silver nanoparticles through bio-inspired polydopamine coating on silicon nanowire arrays for practical SERS applications. Journal of Materials Chemistry B 2(30): 4894-4900.

53. Liu Y, Xu S, Li H, Jian X and Xu W (2011) Localized and propagating surface plasmon co-enhanced Raman spectroscopy based on evanescent field excitation. Chemical Communications 47(13): 3784-3786.

54. Sun X and Li H (2013) Gold nanoisland arrays by repeated deposition and post-deposition annealing for surface-enhanced Raman spectroscopy. Nanotechnology 24(35): article 355706.

55. Loesberg W, Te Riet J, Van Delft F et al. (2007) The threshold at which substrate nanogroove dimensions may influence fibroblast alignment and adhesion. Biomaterials 28(27): 3944-3951.

56. Mirbagheri M, Adibnia V, Hughes BR et al. (2019) Advanced cell culture platforms: a growing quest for emulating natural tissues. Materials Horizons 6(1): 45-71.

57. Maerz T, Mu R and Baker KC (2014) Cell and scaffold surface engineering to enhance cell migration and tissue regeneration. Surface Innovations 2(1): 17-25, https://doi.org/10.1680/si.13.00023.

58. Stevens MM and George JH (2005) Exploring and engineering the cell surface interface. Science 310(5751): 1135-1138.

59. Huang Q, Elkhooly TA, Liu X et al. (2016) Effects of hierarchical micro/nano-topographies on the morphology, proliferation and differentiation of osteoblast-like cells. Colloids and Surfaces B: Biointerfaces 145: 37-45.

60. Çalışkan N, Bayram C, Erdal E, Karahaliloğlu Z and Denkbaş EB (2014) Titania nanotubes with adjustable dimensions for drug reservoir sites and enhanced cell adhesion. Materials Science and Engineering: C 35: 100-105.

61. Kaga N, Akasaka T, Horiuchi R, Yoshida Y and Yokoyama A (2016) Adhesion of Human osteoblast-like cells (Saos-2 cells) on micro/ nanopatterned structures sputter-coated with titanium. Nano Biomedicine 8(2): 74-82.

62. Choi CH, Hagvall SH, Wu BM, Dunn JC and Beygui RE (2007) Cell interaction with three-dimensional sharp-tip nanotopography. Biomaterials 28(9): 1672-1679.

63. Kim E, Lee J, Ahn S, Jeon H and Lee K (2008) Cell culture over nanopatterned surface fabricated by holographic lithography and nanoimprint lithography. Proceedings of the 2008 3rd IEEE International Conference on Nano/Micro Engineered and Molecular Systems, Sanya, China, pp. 725-728.

64. Hoess A, Teuscher N, Thormann A, Aurich H and Heilmann A (2007) Cultivation of hepatoma cell line HepG2 on nanoporous aluminum oxide membranes. Acta Biomaterialia 3(1): 43-50.

65. Ingber DE (2003) Mechanosensation through integrins: cells act locally but think globally. Proceedings of the National Academy of Sciences of the United States of America 100(4): 1472-1474.

66. Curtis A, Gadegaard N, Dalby M et al. (2004) Cells react to nanoscale order and symmetry in their surroundings. IEEE Transactions on Nanobioscience 3(1): 61-65.

\section{How can you contribute?}

To discuss this paper, please submit up to 500 words to the journal office at journals@ice.org.uk. Your contribution will be forwarded to the author(s) for a reply and, if considered appropriate by the editor-in-chief, it will be published as a discussion in a future issue of the journal.

ICE Science journals rely entirely on contributions from the field of materials science and engineering. Information about how to submit your paper online is available at www.icevirtuallibrary.com/page/authors, where you will also find detailed author guidelines. 